\title{
Development of minimum data set for electronic documentation of progress note in the general intensive care unit
}

\author{
Elham Fallahnejad ${ }^{1}$ (D), Fatemeh Niknam², Reza Nikandish Nobar ${ }^{3}$, Farid Zand ${ }^{4}$ (D), Roxana \\ Sharifian ${ }^{* *(D)}$
}

1MSc of Health Information Technology, Shiraz University of Medical Sciences, Shiraz, Iran

${ }^{2} \mathrm{PhD}$ Student of Health Information Management, Shiraz University of Medical Sciences, Shiraz, Iran

${ }^{3}$ Associate Professor, Department of Anesthesiology, School of Medicine, Anesthesiology and Critical Care Research Center, Namazi Teaching Hospital, Shiraz University of Medical Sciences, Shiraz. Iran

${ }^{4}$ Professor, Department of Anesthesiology, School of Medicine, Anesthesiology and Critical Care Research Center, Namazi Teaching Hospital, Shiraz University of Medical Sciences, Shiraz. Iran

${ }^{5}$ Associate Professor, Department of Management \& Medical Information Sciences, Health Human Resources Research Center, School of Management \& Information Sciences, Shiraz University of Medical Sciences, Shiraz, Iran

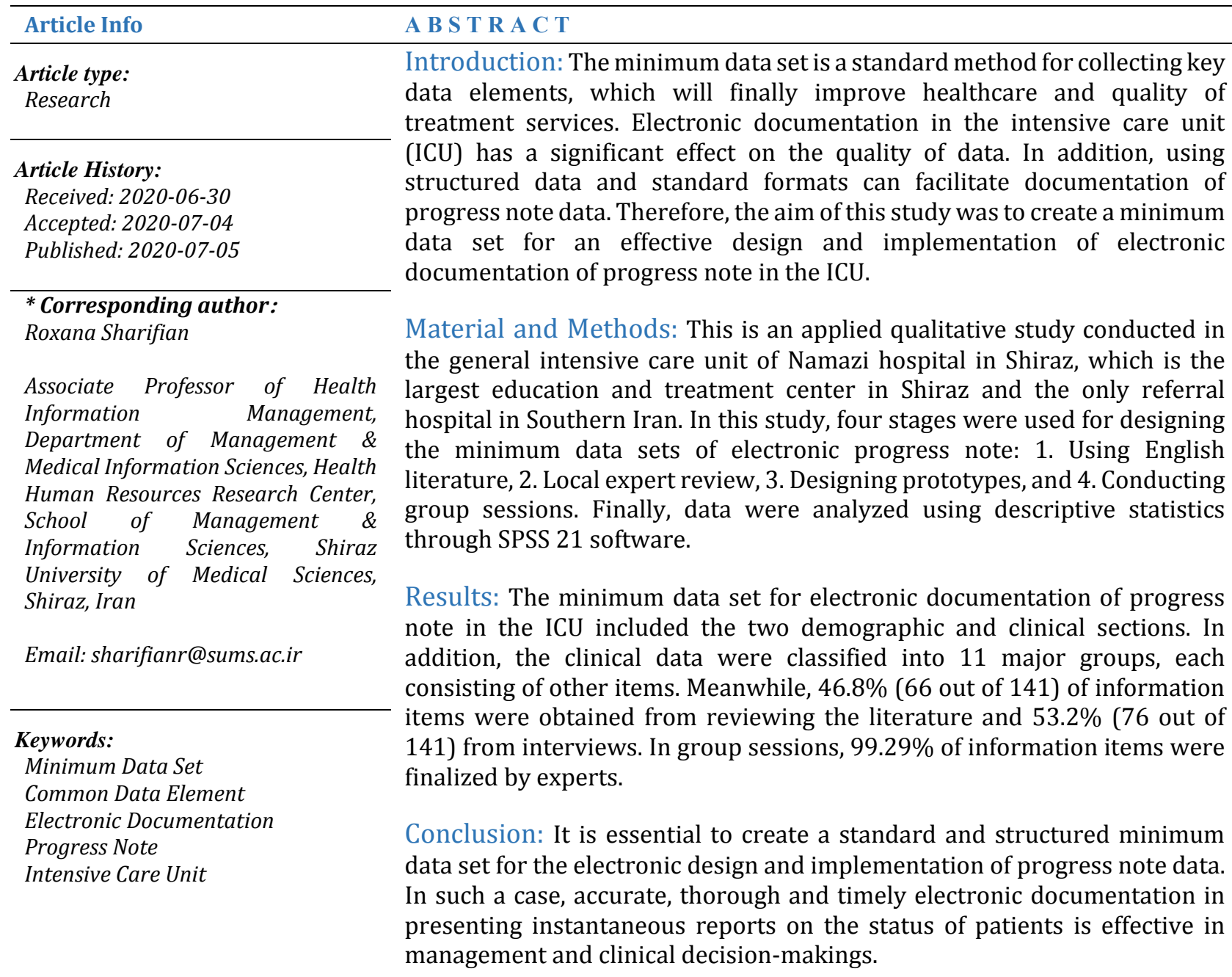

Cite this paper as:

Fallahnejad E, Niknam F, Nikandish Nobar R, Zand F, Sharifian R. Development of Minimum Data Set for Electronic Documentation of Progress Note in the General Intensive Care Unit. Front Health Inform. 2020; 9: 37. D0I: $\underline{10.30699 / \text { fhi.v9i1.226 }}$

\section{INTRODUCTION}

Intensive care unit (ICU) is one of the most important and complex wards in hospitals. It has been estimated that over 1,200 data are produced on a daily basis for taking care of each patient in the ICU, for which an effective strategy for data management in the ICU is required [1]. Studies have shown that electronic documentation in the ICU reduces the workload and is highly effective in the quality of data, in a way that care providers spend more time on taking care of patients as the time of documentation decreases [는 
6].

Electronic health record (EHR) facilitates clinical documentation and patient care by potentially improving legibility and availability of the patient records. Electronic clinical documentation (ECD) is a component of EHR. Increasing use of EHR is considered as an important aspect of the relationship between physicians and other healthcare providers and its major goal is to support the patient care and improve the outcomes. To achieve this goal, documentation should be complete, accurate, timely, and comprehensible for users and should have an appropriate format $[\underline{7}, \underline{8}]$. ECD components include free text, structured data and data which are directly entered into the system. In addition, each data format has a series of limitations and benefits for users when entering and restoring data in electronic documentation. Nonetheless, free texts are not easily searchable and do not generally support features of clinical decision support. However, the entry of structured data can support electronic documentation [9]. In addition, studies recommend using structured data and standard formats for progress note in order to add to the quality of documentation data and facilitate the relations among specialists in the ICU $[\underline{7}, \underline{10}]$.

Minimum data set (MDS) creates a standard method for collecting elements of key data and makes them easier to comprehend. It also creates important sources for planning treatment and continuous assessment of progress note and function. In addition, it provides useful information for healthcare specialists, stakeholders and policymakers, improving the quality of patient care and services [11].

To record progress note in Iran, non-structured paper forms are used, which are capable of timely report of patient status. Since the goal of completing progress note forms is to assess the patient response to treatment and its documentation, the attending physician is obliged to evaluate the patient on a daily basis in terms of disease symptoms, exacerbation or relief of symptoms, progress of clinical findings, results of paraclinical measures, treatment effect, disease complications, adverse effects of treatment, etc. Unfortunately, due to lack of data element in the form of progress note and lack of electronic documentation in Iran, it is possible for the entry of unnecessary, repetitive and insufficient information. Therefore, the aim of this study was to create a MDS for an effective design and implementation of electronic documentation of progress note in the ICU.

\section{MATERIAL AND METHODS}

This is an applied qualitative study conducted in the general intensive care unit of Nemazi Hospital in Shiraz, which is the largest education and treatment center in Shiraz and the only referral hospital in Southern Iran. In this study, four stages were used for designing the minimum data sets of electronic progress note: 1. Using English literature, 2. Local expert review, 3. Designing prototypes, and 4. Conducting group sessions.

\section{Review of English Literature}

At this stage, prestigious databases including Google, PubMed, Google Scholar, ScienceDirect, and EBSCO were searched. The searched keywords included clinical information system, Electronic Health Record, ICU progress note, patient progress note, ICU minimum data set, and daily progress note. In addition, the Google search engine was used for searching prestigious institutes and organizations such as Australian and New Zealand intensive care society (ANZICS) Center for Outcome and Resource Evaluation, Health Resources \& Services Administration, Southwest Texas Medical Associates, Scott \& White Healthcare, and Aboriginal Health Council of South Australia. In addition, the inclusion criteria for the articles were those in English and without time limits. All articles, dissertations, reports and guidelines of the institutes were retrieved and examined. Meanwhile, websites of all the mentioned institutes were visited and all documents relating to the research goal were explored. Finally, data were collected through extracted forms.

\section{Local Expert Review}

After necessary coordination was made and the objective of the interview was thoroughly explained to interviewees, five interviews with an average duration of one hour and six minutes were held in a calm environment with five local experts. The questions that interviewees were asked during the interviews included: What do users of this system expect from the related system? What is the work process and daily measures of physicians like? Finally, what items and information are necessary for the system from the point of view of the physician? In addition, a voice recorder was used for recording all of what interviewees said. After the interviews were over, the results were analyzed following several careful reviews by the researcher. After data were collected at this stage, some documents relating to the requirements were prepared and then they were reexamined by the relevant interviewees. Finally, necessary modifications were made.

\section{Prototype Design}

At this stage, the researcher used the PowerPoint program to design a prototype from the known data elements that had been obtained in two earlier stages. The prototype had 12 sections: 1 . Patient Admission \& Demographic Data 2. Brief History Significant event \& Issues 3. Respiratory System 4. 
Cardiovascular system 5. Neurologic 6. Renal 7. Gastrointestinal 8. Microbiology 9. Hematology 10. Skin 11. Plan 12. Problem List.

\section{Conducting group sessions}

To investigate and discuss the components of the designed prototype, five group sessions with an average duration of one hour and 10 minutes were held with 11 experts (six ICU subspecialists and specialists, three computer engineers, one $\mathrm{PhD}$ in health information management, and one expert with Master of Science in health information technology). Meanwhile, according to their views, a number of items were eliminated. All the documents were recorded and classified by the researcher. Finally, at the quantitative stage of the study, the data were analyzed using descriptive statistics (frequency and percentage) through SPSS 21 software.

\section{RESULTS}

After five group sessions and exchanging views with experts, 141 information items were achieved for electronic documentation of progress note, which included two demographic and clinical sections. In addition, clinical data were classified into 11 major groups, with each group including other items (Table 1).

Based on the results of the study, $46.8 \%$ (66 out of 141) information items were achieved from reviewing the literature and $53.2 \%$ (72 out of 141 ) from interviews. During group sessions, 99.29\% of the information items were finalized by experts.

Table 1: Minimum Data Set for Electronic Documentation of Progress Note in the General Intensive Care Unit

\begin{tabular}{|c|c|}
\hline $\begin{array}{c}\text { Type of } \\
\text { Information }\end{array}$ & Data Element \\
\hline $\begin{array}{l}\text { Patient } \\
\text { Admission \& } \\
\text { Demographic }\end{array}$ & $\begin{array}{l}\text { First name, last name, Bed number, } \\
\text { Gender, Date of birth, Age, Medical } \\
\text { Record Number, Patient Code, } \\
\text { National Code, Hospital Admission } \\
\text { Date, ICU Admission Date, Hospital } \\
\text { Admission Source, ICU Admission } \\
\text { Source, Day of ICU Admission, } \\
\text { primary diagnosis, ICU diagnosis, } \\
\text { Referring physician, ICU Attending, } \\
\text { Weight, Height }\end{array}$ \\
\hline $\begin{array}{l}\text { Brief History } \\
\text { Significant } \\
\text { event \& Issues }\end{array}$ & $\begin{array}{l}\text { Drug History, Drug Allergy, Family } \\
\text { History, Habits, ICU Course, Major } \\
\text { Physical Exam Finding, Major Event, } \\
\text { Major Issue }\end{array}$ \\
\hline $\begin{array}{l}\text { Respiratory } \\
\text { System }\end{array}$ & $\begin{array}{l}\text { Respiratory Support, } \mathrm{O}_{2} \text { Therapy, Air } \\
\text { Way, ETT Size, TT Size, Fixed at, Cuff } \\
\text { Pressure, Air Entry, Breath sound, } \\
\text { Respiratory Effort, Last order of } \\
\text { mode of ventilation, TV Set, } \\
\text { Inspiratory Pressure, Respiratory } \\
\text { Frequency, } \Delta \text { Pressure Support, } \\
\text { Positive end-expiratory pressure } \\
\text { (PEEP), Flow, FiO } 2 \text {, Pmax, }\end{array}$ \\
\hline
\end{tabular}

\begin{tabular}{|c|c|}
\hline $\begin{array}{c}\text { Type of } \\
\text { Information }\end{array}$ & Data Element \\
\hline & $\begin{array}{l}\text { Humidification, } \\
\text { Inspiration/expiration time ratio, } \\
\text { Minute Ventilation, Compliance, } \\
\text { Resistance, Spontaneous Respiratory } \\
\text { Rate, SBT Was down, RSBI on } \\
\text { Pressure Support, Pao2/Fio2, , Peak } \\
\text { Airway Pressure, Plateau Airway } \\
\text { Pressure, } \mathrm{SPO}_{2} \text {,, End-tidal CO2, Chest } \\
\text { Tube/Drain ( } 24 \text { hour), Tracheal } \\
\text { Aspirate, } \mathrm{PH}, \mathrm{P}_{2} \mathrm{CO}_{2}, \mathrm{P}_{2} \mathrm{O}_{2}, \mathrm{HCO}_{3}^{-}, \mathrm{BE} \text {, } \\
\mathrm{O}_{2} \text { sAT, Head of bed elevated }>30 \\
\text { degrees? }\end{array}$ \\
\hline $\begin{array}{l}\text { Cardiovascular } \\
\text { system }\end{array}$ & $\begin{array}{l}\text { Heart Rate, Blood Pressure, Systolic, } \\
\text { Diastolic, type of central line, site of } \\
\text { central line, CVP, Rhythm, DVT } \\
\text { Prophylaxis, Signs of DVT, Four point } \\
\text { sono, Heart Sound, Troponin, pitting } \\
\text { edema, Extremities, advanced } \\
\text { hemodynamic indexes, New Echo } \\
\text { Findings (EF, RV Size, TRG, IVC Size, } \\
\text { Collapsibility, Pericardial effusion), } \\
\text { Vasoactive medications }\end{array}$ \\
\hline Neurologic & $\begin{array}{l}\text { RASS Score, Neurologic State, GCS } \\
\text { (Best Motor, Best Verbal, Eye } \\
\text { Opening), Brain CT, ICP, Seizure, } \\
\text { Plantar Reflex, Pupils, Muscle Power, } \\
\text { Last LP (Opening pressure, cell count, } \\
\text { RBC, Lymphocyte, PMN, Protein, } \\
\text { Sugar), Sedatives, sedative } \\
\text { medications, Sedation Vacation, } \\
\text { Neuromuscular Blockers }\end{array}$ \\
\hline Renal & $\begin{array}{l}\text { IV Fluids, Urine Output, Total Intake, } \\
\text { Total Output, Balance, Renal } \\
\text { replacement Therapy ,RRT Order, } \\
\text { CRRT Order, BUN, Cr, Na, K, CL, Mg, } \\
\text { Ca, P }\end{array}$ \\
\hline Gastrointestinal & $\begin{array}{l}\text { Abdominal Exam, NPO, Reason for } \\
\text { NPO, PO Fed (Rate, Type of Feeding), } \\
\text { Enteral Feeding (Rate, Type of } \\
\text { Feeding), Total Calorie (Goal Calorie, } \\
\text { Received Calorie, Ordered Calorie), } \\
\text { TPN (Amino acid, Lipids, Dextrose), } \\
\text { Bowel sounds, Bowel Movement, } \\
\text { Consistency of stool, Blood Glucose } \\
\text { Control, Stress Ulcer Prophylaxis, } \\
\text { Other New Laboratory Results }\end{array}$ \\
\hline Microbiology & $\begin{array}{l}\text { Temperature, Current Temperature, } \\
\text { Type of Culture (Blood, TT/ETT, } \\
\text { urine, wound, BAL, Fluid), Result of } \\
\text { Culture (Date of Request, Date of } \\
\text { Response, Type of Organism, } \\
\text { Sensitive to, Resistant to, } \\
\text { Intermediate), Type of Antibiotic, } \\
\text { Reason for starting, Start Date, Stop } \\
\text { Date, Laboratory Result (ESR, CRP, } \\
\text { procalcitonin, serum lactate) }\end{array}$ \\
\hline Hematology & $\begin{array}{l}\text { Hb, HCT, WBC, Platelet, Retic count, } \\
\text { PBS }\end{array}$ \\
\hline Skin & $\begin{array}{l}\text { Pressure Ulcer, NPUAP Grade, New } \\
\text { Skin lesions }\end{array}$ \\
\hline \multicolumn{2}{|l|}{ Plan } \\
\hline Problem List & \\
\hline
\end{tabular}




\section{DISCUSSION}

In the present study, experts approved 141 information items for electronic documentation of progress note. These items can be easily compatible with electronic environments. According to search made, no previous studies have so far achieved these 141 information items $[\underline{7}, \underline{12}]$. In fact, this is the first study that has created the minimum data set for progress note in the general ICUs. The minimum data set creates a standard method for processing and collecting data in healthcare systems. Therefore, they are considered as one of the factors for organizations to have achieve efficacy and efficiency [12-14].

The minimum data set for electronic documentation in the ICU includes the two components of demographic data and clinical data. Demographic data are collected to identify the patients and provide the relationship between healthcare providers and patients. Therefore, it is one of the most important and essential data that should be completed before the onset of treatment for the purpose of identifying and following up the patient by the treatment staff. In addition, clinical data which are collected during the treatment of the patient by healthcare providers facilitates medical education, research and planning [15].

The study by Klundert showed that demographic data, management data, and clinical data (glasgow coma score, blood pressure, heart and respiratory rate, blood gas arterial, body temperature, urine output, etc.) were collected for all inpatients in the ICU in the Netherlands Intensive Care Evaluation Registry [16], which are compatible with the results of this study while these data have been approved by experts in the group sessions.

In addition, ANZICS has provided a minimum data set for ICU inpatients. The data include biochemical, physiological and demographic data, which are collected on a daily basis during the process of treating ICU inpatients [17]. All of those data are compatible with the data in the present study. However, in our study, physiological and biochemical data were classified as a sub-category of clinical data according to the views of experts. Thus, these data did not need to be isolated from one another.

Southwest Texas Medical Associates organizes the daily progress note in the electronic health record in 12 sections, which are all compatible with our study except for data relating to measures. To record the measures, hospitals need to connect the electronic documentation system with other clinical information systems. In addition, this association has implemented EHR in their hospitals, which are connected to other systems [18]. However, EHR has not yet been implemented in Iran and hospital information systems currently focus only on administrative data of the patients.
The study conducted by Kalankash revealed that the minimum data set for the registry system of cystic fibrosis include 45 data elements [19] and all the demographic data, except for body mass index (BMI), in the cystic fibrosis registry were compatible with our study because BMI is generally used for evaluating the nutrition conditions in cystic fibrosis (CF) patients [20]. However, in our study, experts did not include BMI as essential elements. Meanwhile, in reviewing the literature, no reference was made to BMI in ICU clinical information systems [16-18].

The results of the study by Jahanbakhsh suggested that the most minimum data sets for diabetes mellitus included the two demographic and clinical data sections [15]; this finding is similar to those of the present study. In addition, Ahmadvand designed a minimum data set for the echocardiography reporting system for electronic health records in Iran. The results of the study by Ahmadvand are compatible with those of our study in demographic information, laboratory results, history, and clinical

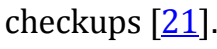

\section{CONCLUSION}

In this study, experts approved 141 information items for electronic documentation of progress note. Therefore, a standard and structured MDS is essential for electronic design and implementation of progress note data. In such a case, accurate, thorough and timely electronic documentation in presenting instantaneous reports on the status of the patient is effective in management and clinical decisionmakings, better relations with physicians, and support of research and training residents. It is also an effective solution for eliminating problems induced by paper-based documentation, contributing to the completion of records, and preventing loss of information in the ICU. Therefore, by familiarizing all users with MDS and electronic documentation in the ICU as well as providing appropriate infrastructure for implementation of electronic documentation, one can take a step towards improving the health system.

The lack of research in this field on the Iranian community that can be used to compared with our study in discussion and limited setting of the study are some of the limitations which should be considered in future studies.

\section{ACKNOWLEDGEMENT}

The present article was adopted from Mrs. Elham Fallahnejad MSc. thesis in Health Information Technology, Faculty of Management and Medical Information Sciences, Health Human Resource Center, Shiraz University of Medical Sciences, Shiraz, Iran. The authors would like to thank the Research Vice-Chancellor of Shiraz University of Medical Sciences for financially supporting the research 
(Contract No. 95-01-07-11326).

\section{AUTHOR'S CONTRIBUTION}

Study development and design: EF, RNN and RS. Data analysis and data collection: EF, FN and, FZ. Paper preparation: EF, RNN, RS, FN and FZ. All the authors approved the final version of the manuscript.

CONFLICTS OF INTEREST
The authors declare no conflicts of interest regarding the publication of this study.

\section{FINANCIAL DISCLOSURE}

This study has been financially supported by Shiraz University of Medical Sciences (Contract No. 95-0107-11326).

\section{REFERENCES}

1. Pickering BW, Dong Y, Ahmed A, Giri J, Kilickaya O, Gupta A, et al. The implementation of clinician designed, human-centered electronic medical record viewer in the intensive care unit: A pilot step-wedge cluster randomized trial. Int J Med Inform. 2015; 84(5): 299-307. PMID: 25683227 DOI: 10.1016/j.ijmedinf.2015.01.017 [PubMed]

2. Bosman R. Impact of computerized information systems on workload in operating room and intensive care unit. Best Pract Res Clin Anaesthesiol. 2009; 23(1): 15-26. PMID: 19449613 DOI: 10.1016/j.bpa.2008.10.001 [PubMed]

3. Bosman R, Rood E, Oudemans-van Straaten H, Van der Spoel J, Wester J, Zandstra D. Intensive care information system reduces documentation time of the nurses after cardiothoracic surgery. Intensive Care Med. 2003; 29(1): 83-90. PMID: 12528027 DOI: 10.1007/s00134-002-1542-9 [PubMed]

4. Carayon P, Wetterneck TB, Alyousef B, Brown RL, Cartmill RS, McGuire K, et al. Impact of electronic health record technology on the work and workflow of physicians in the intensive care unit. Int J Med Inform. 2015; 84(8): 578-94. PMID: 25910685 DOI: 10.1016/j.ijmedinf.2015.04.002 [PubMed]

5. Ehteshami A, Sadoughi F, Ahmadi M, Kashefi P. Intensive care information system impacts. Acta Inform Med. 2013; 21(3): 185-91. PMID: 24167389 DOI: 10.5455/aim.2013.21.185-191 [PubMed]

6. De Georgia MA, Kaffashi F, Jacono FJ, Loparo KA. Information technology in critical care: Review of monitoring and data acquisition systems for patient care and research. Scientific World Journal. 2015; 2015: 727694. PMID: 25734185 DOI: 10.1155/2015/727694 [PubMed]

7. Daphtary K. Computerized clinical documentation in the pediatric intensive care unit: Quality of notes and factors that affect the quality [Master Thesis]. Oregon Health \& Science University; 2014.

8. Schiff GD, Bates DW. Can electronic clinical documentation help prevent diagnostic errors? N Engl J Med. 2010; 362(12): 1066-9. PMID: 20335582 DOI: 10.1056/NEJMp0911734 [PubMed]

9. Brown PJ, Marquard JL, Amster B, Romoser M, Friderici J, Goff S, et al. What do physicians read (and ignore) in electronic progress notes? Appl Clin Inform. 2014; 5(2): 430-44. PMID: 25024759 DOI:

\subsection{8/ACI-2014-01-RA-0003 [ubMed]}

10. Leigh JP, Kamran H, Dodek PM, Bagshaw SM, Forster AJ, Turgeon AF, et al. Textual analysis of physician progress notes for patients transferred from the intensive care unit to hospital ward. American Journal of Respiratory and Critical Care Medicine. 2017; 195: A7084.

11. Sadoughi F, Nasiri S, Langarizadeh M. Necessity for designing national minimum data set of perinatal period in Iran: A review article. Medical Journal of Mashhad University of Medical Sciences. 2014; 57(5): 727-37.

12. Sadoughi F, Shahi M, Ahmadi M, Davaridolatabadi N. The comparison of the minimum data set for elderly health in selected countries. Acta Inform Med. 2015; 23(6): $\quad 393-7 . \quad$ PMID: 26862252 DOI: 10.5455/aim.2015.23.393-397 [ [PubMed]

13. Embi PJ, Yackel TR, Logan JR, Bowen JL, Cooney TG, Gorman PN. Impacts of computerized physician documentation in a teaching hospital: Perceptions of faculty and resident physicians. J Am Med Inform Assoc. 2004; 11(4): 300-9. PMID: 15064287 DOI: 10.1197/jamia.M1525 [PubMed]

14. Karimi S, Saghaeian Nejad Isfahani S, Farzandipour M, Esmaeili Ghayoumabadi M. Comparative study of minimum data sets of health information management of organ transplantation in selected countries and presenting appropriate solution for Iran. Health Information Management. 2011; 7: 497 505.

15. Jahanbakhsh M, Moghaddasi H, Hosseini A. Designing of diabetic mellitus minimum data sets: Indicator basis of diabetic management effectiveness. Health Information Management. 2010;7(3): 330-40.

16. van de Klundert N, Holman R, Dongelmans DA, de Keizer NF. Data resource profile: The Dutch national intensive care evaluation (NICE) registry of admissions to adult intensive care units. Int J Epidemiol. 2015; 44(6): 1850-1850h. PMID: 26613713 DOI: 10.1093/ije/dyv291 [PubMed]

17. Australian and New Zealand Intensive Care Society. Adult patient database (APD): Data dictionary for software programmers [Internet]. 2013 [cited: 1 Jun 2020]. Available from: https://www.anzics.com.au/adult-patient-databaseapd/

18. Southwest Texas Medical Associates. Hospital daily progress note tutorial [Internet]. 2007 [cited: 1 Jun 
2020]. Available from: http://www.setma.com/EPMTools/tutorial-daily-progress-note.

19. Kalankesh LR, Dastgiri S, Rafeey M, Rasouli N, Vahedi L. Minimum data set for cystic fibrosis registry: A case study in Iran. Acta Inform Med. 2015; 23(1): 18-21. PMID: 25870486 doi: 10.5455/aim.2015.23.18-21 [PubMed]

20. Sheikh S, Zemel BS, Stallings VA, Rubenstein RC, Kelly A. Body composition and pulmonary function in cystic fibrosis. Front Pediatr. 2014; 2: 33. PMID: 24783186 DOI: 10.3389/fped.2014.00033 [PubMed]

21. Mahmoudvand Z, Kamkar M, Shahmoradi L, Nejad AF. Determination of minimum data set (MSD) in echocardiography reporting system to exchange with Iran's electronic health record (EHR) system. Acta Inform Med. 2016; 24(2): 116-9. PMID: 27147803 DOI: 10.5455/aim.2016.24.116-119 [PubMed] 